\title{
Development of an early warning system for shallow landslide in the Grasberg area, Indonesia
}

\author{
P Farina Geoapp S.r.I., Italy \\ F Catani Geoapp S.r.I. and Università degli Studi di Firenze, Italy \\ A Rosi Geoapp S.r.I. and Università degli Studi di Firenze, Italy \\ I Setiawan PT Freeport Indonesia, Indonesia
}

A Junaidi PT Freeport Indonesia, Indonesia

K Afrizal PT Freeport Indonesia, Indonesia

A Wijayanto PT Freeport Indonesia, Indonesia

\begin{abstract}
In the middle of the 20th century, one of the largest open pit mining facilities in the world was established at Grasberg on top of the main Papuan ridge. In time, this expanded to become the most notable man-made landscape feature on the entire island. Mining operations are supported by a large array of workshops and facilities, scattered from the top of the mountain down to the seashore. They include large camps and mining villages hosting the workforce and their families.

In this work, we present the results of a project to help mining company staff define triggers for an early warning system (EWS) for shallow landslides using meteorological forecasts and rain gauge measurements. This would help to mitigate the risk for the Grasberg mine and surrounding valleys of sudden detachment, routing and runout of shallow landslides.
\end{abstract}

To achieve such a scope, the work has been split into three main tasks:

1. Definition of rainfall thresholds for the initiation of shallow landslides in the broader Grasberg area based on cumulative rainfall thresholds (CRT) and intensity-duration thresholds (IDT).

2. Development of a hazard map for shallow landslides, including predictions of initial location, runout and volumes of sediment involved using a state-of-the-art machine learning multivariate statistical analysis tool called Random Forests (RF).

3. Setup of an EWS based on the rainfall thresholds and support for the implementation of the operational chain of risk mitigation routine procedures already in place.

Keywords: landslide hazard mapping, early warning systems, machine learning

\section{Introduction}

Landslides are a natural hazard resulting in a high number of casualties and economic losses each year (Petley 2012). To reduce the impact of landslides, several approaches have been developed with the aim of assessing both landslide prone areas (Catani et al. 2013) and landslide triggering conditions (Rosi et al. 2016, 2019). These approaches can be divided into two main categories: deterministic and statistical (or empirical). Deterministic approaches are more reliable, but they require a high number of parameters (e.g. geotechnical parameters), which are often difficult to collect and their computational load is often high. For these reasons, they are usually applied to small areas such as a single slope or over small drainage basins (Guzzetti et al. 2007). 
Statistical approaches are less reliable, but they require a smaller amount of data (with a lower precision). These are more suitable for use over wide areas, where high-quality data cannot be easily obtained (Brunsden 1973).

Deterministic approaches usually lead to the definition of a slope Factor of Safety, while the more common statistical ones lead to the definition of a degree of probability of landslides or of triggering of landslides, through the definition of landslide susceptibility maps (Catani et al. 2013) and rainfall thresholds (e.g. Rosi et al. 2016, 2019), respectively.

In an operational framework (Rosi et al. 2017; Segoni et al. 2018), the above-described approaches have to be integrated to develop a landslide EWS, capable of identifying the triggering conditions and the areas where landslides are more likely to occur.

In this paper, the work carried out to mitigate the landslide risk in the Grasberg district (Indonesia) is presented.

In the area, one of the largest open pit mining facilities in the world was established in the early 1990s and included a large number of workshops, facilities and services extending from the open pit mine site at the top of the mountain down to the seashore. This area is characterised by an equatorial climate with a high rainfall rate without significant variations over the year, while elevations range from over 4,000 $\mathrm{m}$ a.s.l. (above sea level), near the open pit crest to the sea level. The study area is affected by landslide phenomena, which are mainly surficial and usually triggered by rainfall.

The study achieved three main tasks:

1. Definition of rainfall thresholds based on a combination of cumulative rainfall thresholds (CRT) that consider the rainfall up to 30 days, and intensity-duration thresholds (IDT) that consider only the rainfall of the triggering event with a duration of a few hours, up to 1-2 days.

2. Development of a landslide hazard (susceptibility) map for shallow landslides over the studied area using a machine learning approach named Random Forests (RF) coupled with the mapping of the runout path of possible landslides.

3. Development of a spatially variable early warning system (EWS) based on a combination of IDT and CRT where the spatial variability was obtained by the definition of a 'reference area' of each rain gauge.

In this paper, the methodologies used to achieve the above-mentioned tasks are presented, as well as their results, advantages and drawbacks.

\section{Methodology}

\subsection{Rainfall thresholds}

Of the several landslide triggering mechanisms, rainfall is the most common and the definition of rainfall thresholds is the most used approach to identify the triggering condition of landslides. In this work, two kinds of thresholds have been calculated: one based on the intensity and duration of the triggering event according to the approach proposed by Caine (1980) and the other based on rainfall anomalies (expressed as multiples of standard deviation of rainfall distribution) over fixed time intervals (Benedetti et al. 2005). 


\subsubsection{Intensity-duration threshold}

The IDT approach is based on identifying critical rainfall responsible for landslide triggering, that starts from the date and location of known landslide events, to trace a threshold based on the Caine (1980) equation:

$$
I=\alpha D^{-\beta}
$$

where:

$$
\begin{aligned}
& D=\text { rainfall event duration (in hours) } . \\
& 1=\text { rainfall intensity }(\mathrm{mm} / \mathrm{h}) .
\end{aligned}
$$

defined as the ratio between the total rainfall recorded during the event $(C$, in $\mathrm{mm})$ and the duration $\mathrm{D}(\mathrm{I}=\mathrm{C} / \mathrm{D})$.

The I-D values of several rainfall events that triggered landslides are then plotted in a log-log diagram to identify a threshold, i.e. a boundary that theoretically can divide rainfall that triggered landslide and rainfall that did not trigger landslides. A supervised approach based on the definition of the I-D values of rainfall events that triggered landslides was used to define the thresholds. The work based on this approach started from the analysis of a series of 92 rainfall events that triggered 132 landslides (including debris flows, shallow landslides, soil slips) from 2006 to 2017 with known location, date and time of occurrence; rainfall data have been gathered from a network of 26 rain gauges (Figure Figure 1).

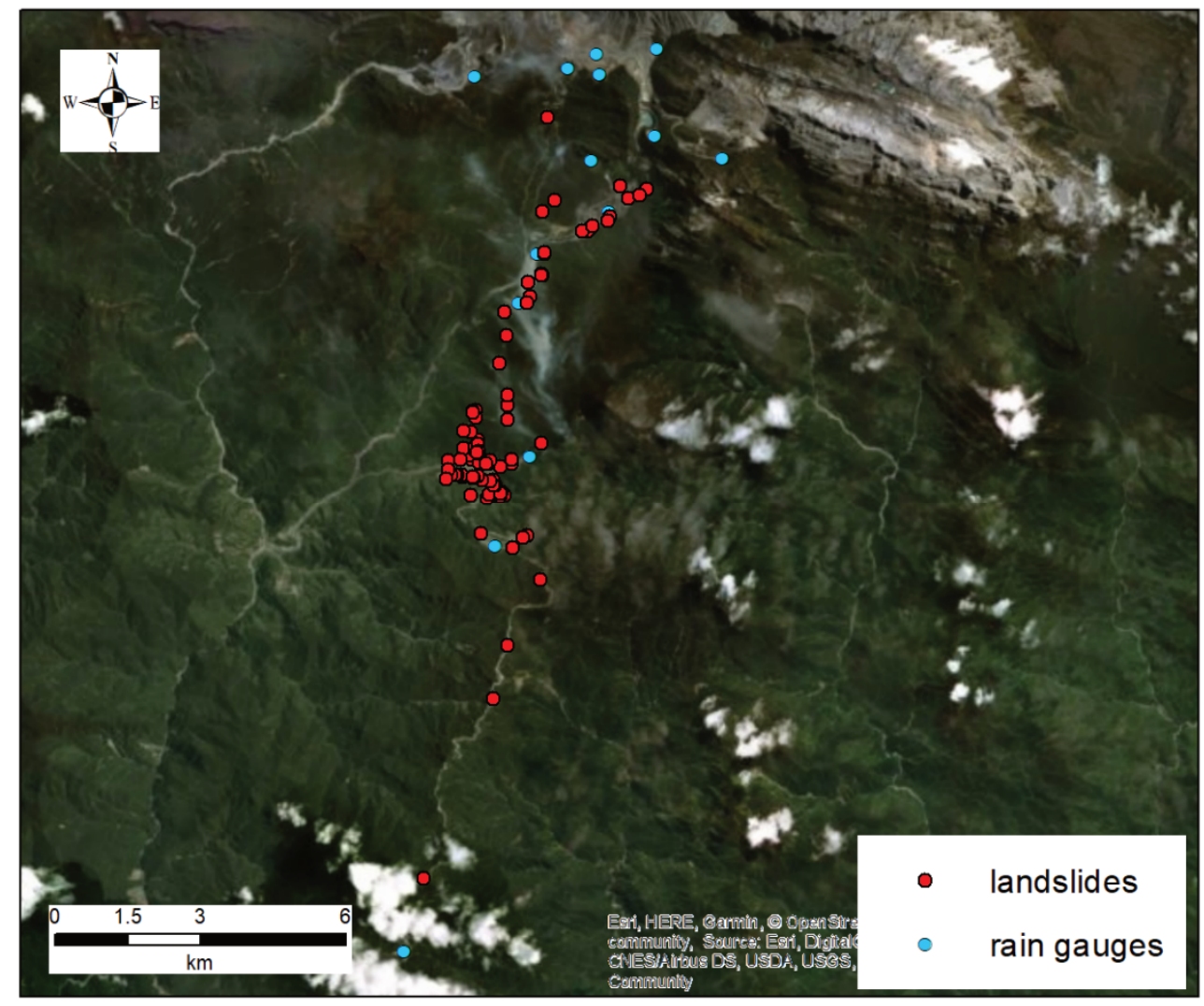

Figure 1 Map showing the distribution of landslides and rain gauges (some rain gauges are not present in the figure as they are far from the landslides)

These data were used to define a threshold system, based on three subsequent rainfall thresholds that define four alert levels (No Warning, Standby, Caution and Warning). This threshold system has been designed to minimise the number of missed alarms as much as possible, but also to reduce the number of false alarms for higher-level thresholds, i.e. the number of false alarms in Warning level should be sensibly lower than one in Standby or Caution level. The minimisation of missed alarms can also compensate the number of missed alarms of the CRT approach as described in Section 2.3. 


\subsubsection{Cumulative rainfall thresholds}

The CRT approach is based on the premise that rainfall-induced landslides are due to 'anomalous' rainfall, i.e. to rainfall events that are in some way different from 'regular' rainfall events. These anomalous events (outliers) are usually characterised by a lower probability of occurrence than regular events, so we used this difference in probability to differentiate anomalous and regular rainfall events.

To identify the outliers, we used the approach proposed by Martelloni et al. (2012), the Sigma model that is based on the analysis of standard deviation of rainfall data series. In a certain data series, standard deviation and probability occurrence of a value are linked with a proportional relationship (e.g. values ranging up to $\pm 1 \sigma$ from mean value have a probability of occurrence of $66 \%$ ), so anomalous events that have a low occurrence probability can be identified by the analysis of standard deviation values of rainfall time series. The procedure was repeated for each time interval $n(1 \leq n \leq 720)$ for each rain gauge.

All cumulative rainfall series were characterised by an asymmetric distribution; the statistical cumulative distributions tend toward lognormal for short periods and toward normal for long periods, but in neither case are these theoretic distributions fully matched (Benedetti et al. 2005). Therefore, to obtain probability values not exceeding a given rainfall threshold, the data of the original distributions are adapted to a target function chosen as a model (Goovaerts 1997), in this case, the standard Gaussian distribution. This transformation relates the values of the original series of the cumulative rainfall $(z)$ and distribution target $(y=\alpha \cdot \sigma)$, where $\alpha$ is a constant and $\sigma$ is the standard deviation. Each series of cumulative rainfall is sorted in ascending order and a standard statistical index (plotting position) is used as cumulative sample frequency and the transformed value $y$ on the original data $z$ is obtained as the quantile of the distribution target. Once the described transformation has taken effect, we can select a probability of not overcoming and applying the procedure in reverse order; to be more precise, from a particular value of $\sigma$ or its multiples, we calculated the corresponding cumulative frequency sample and from this value the precipitation (in $\mathrm{mm}$ ) of the original series.

Proceeding in the same way for the number of cumulative rainfalls between 1 and 30 days, we built the precipitation curves ( $\sigma$ curves) associated with various probabilities of not being overcome (2- $\sigma$ curve is related to a probability of not overcoming lower than $5 \%$ ). In this approach, multiples of the standard deviation $(\sigma)$ are used as thresholds to discriminate between ordinary and extraordinary rainfall events. Starting from the original series of hourly precipitation, the time series of accumulated data from 1 to 30 days was built for each rain gauge. To obtain the n-days' time series of a rain gauge, the hourly recordings are cumulated at $\mathrm{n}$-hour intervals, with an $\mathrm{n}$-hours wide moving window shifting at 1-hour time steps along the whole rainfall record of the instrument.

The aforementioned $\sigma$ curves are implemented in a decisional algorithm that constitutes the core of the Sigma model. The latter operates separately for rain gauge, and in real-time applications the model works at hourly time steps providing an alert level that depends on rainfall recordings, or weather forecast if available. For each rain gauge, the rainfall amounts are accumulated at increasing time intervals ranging from 1 to 720 hours and these values are compared with the $\sigma$ curves, which are used as thresholds (Figure 2).

The CRT algorithm is based on the comparison between rainfall records and sigma curves to identify the rainfall responsible for the triggering of the landslides. It is designed to give four alert levels, on the basis the number of false alarms, missed alarms and correct alarms. To define the algorithm, landslide data from 2013 to 2017 were initially used and the cumulative rainfall at several time steps was calculated $(1,2,3,7,10,15$ and 30 days) for each rainfall event that triggered landslides ( 29 events that triggered 54 landslides). To identify the rainfalls responsible for the triggering of landslides, rainfall data were compared with several $\sigma$ values $(1,1.25,1.5,1.75,2,2.25,2.5,2.75,3)$ for each time interval; in this way a combination of seven time intervals and $9 \sigma$ values were obtained (Table 1 ). 


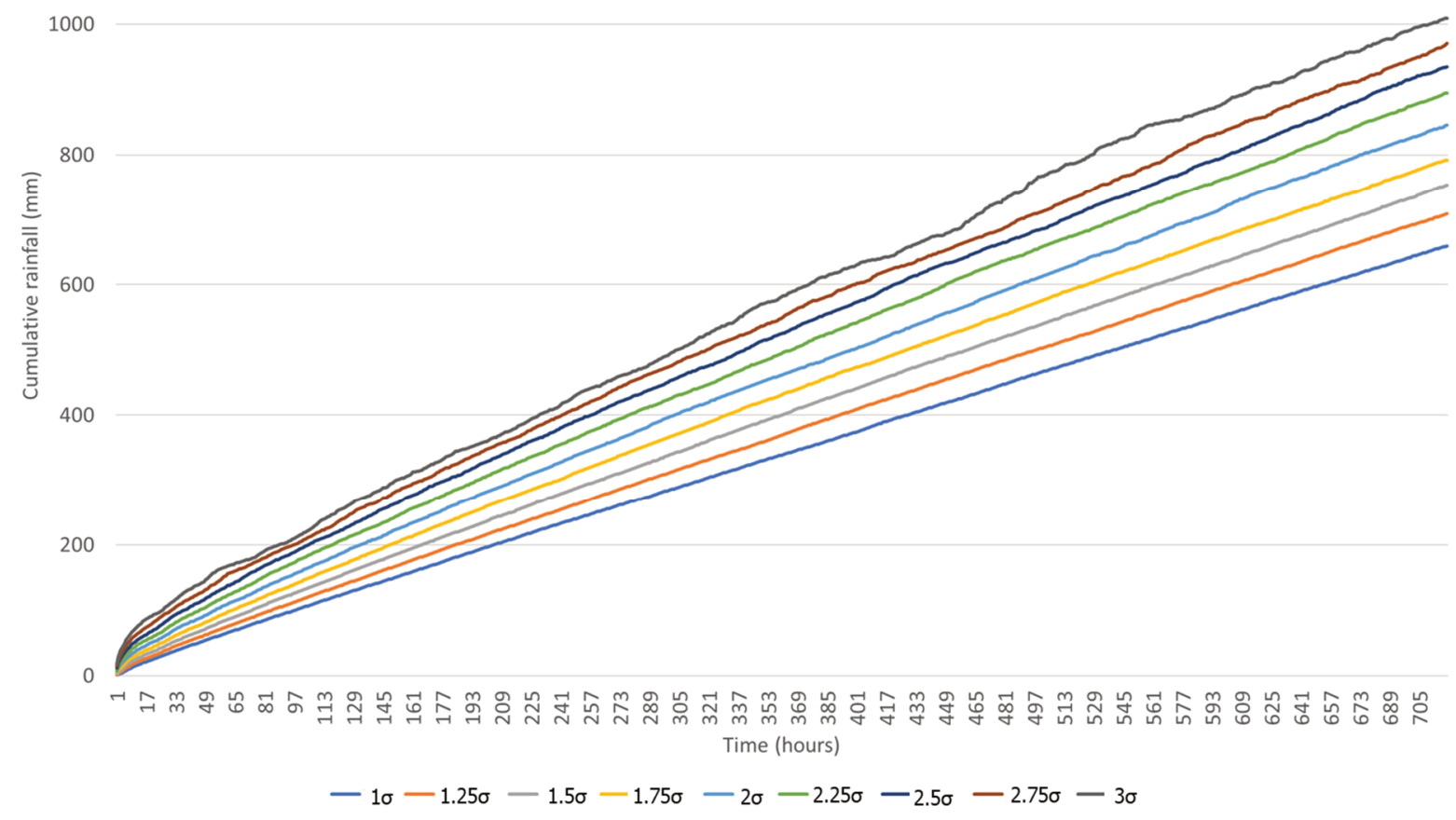

Figure 2 Example of rainfall probability curves ( $\sigma$ curves) in a cumulative period up to 30 days

Table $1 \quad \sigma$ values calculated for several time intervals

\begin{tabular}{|c|c|c|c|c|c|c|c|c|c|}
\hline \multirow{2}{*}{$\begin{array}{l}\text { Time } \\
\text { interval } \\
\text { (days) }\end{array}$} & \multicolumn{9}{|c|}{$\sigma$ values } \\
\hline & $1 \sigma$ & $1.25 \sigma$ & $1.5 \sigma$ & $1.75 \sigma$ & $2 \sigma$ & $2.25 \sigma$ & $2.5 \sigma$ & $2.75 \sigma$ & $3 \sigma$ \\
\hline 1 & 28.70 & 34.4 & 41.2 & 48.4 & 56 & 64.514 & 75.4 & 88.146 & 96.6 \\
\hline 2 & 53.2 & 61.2 & 70.4 & 80.2 & 91 & 102.8 & 116 & 129.6 & 143 \\
\hline 3 & 76.4 & 86.8 & 97.8 & 110.4 & 122.8 & 137.8 & 154.9 & 168.8 & 177 \\
\hline 7 & 165.72 & 183.8 & 202.2 & 221.8 & 242 & 264.16 & 286.2 & 301.8 & 318.8 \\
\hline 10 & 232.2 & 253.4 & 278.2 & 300.2 & 326.4 & 354.4 & 378.2 & 397.4 & 413.6 \\
\hline 15 & 338.58 & 368.8 & 399.8 & 430.8 & 461.4 & 494.2 & 524.8 & 547.6 & 580.8 \\
\hline 30 & 659.4 & 709 & 753.6 & 792 & 845.8 & 894.8 & 934.4 & 971 & $1,008.8$ \\
\hline
\end{tabular}

Calculated rainfall amounts for each landslide event (and each time interval), have then been compared with $\sigma$ values and the number of correct alarm (CA), missed alarm (MA) and false alarm (FA) was calculated for each combination.

CA, MA and FA values have been subsequently used to calculate several statistical indices, useful to understand which $\sigma$ values combinations gave the best results; $3 \sigma$ values were not considered since the number of CA was generally too low and number of MA too high.

The following statistical indices have been calculated:

- Sensitivity (Se): CA/(CA+MA).

- Positive prediction value (PPV): CA/(CA+FA).

- Performance index (PI): CA/(FA+MA). 
Higher values of sensitivity have been achieved for lower $\sigma$ - time interval pairs. This implies a high number of correct alarms with a low number of missed alarms; the value decreases with increasing time intervals or $\sigma$ values. These results were considered to define an algorithm capable of balancing the number of CA, FA and MA that was developed by trial and error, i.e. several combinations of time interval and $\sigma$ were tested with the available data until the best result was obtained. The best result was obtained considering rainfall of 1-2 days before the landslide but also with 30 days cumulative rainfall (Figure 3 ).

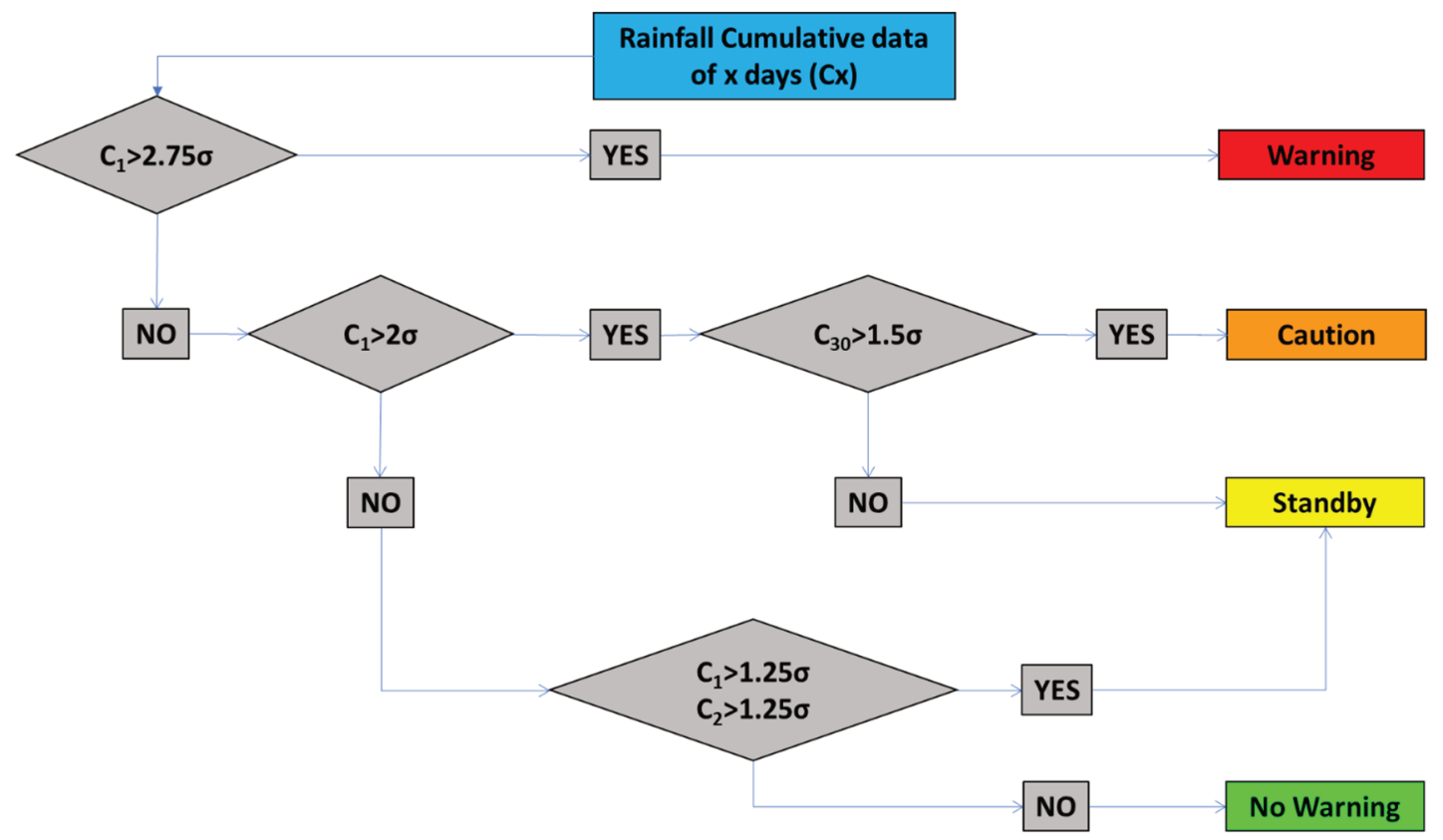

Figure 3 Structure of the cumulative rainfall thresholds algorithm

\subsubsection{Intensity-duration thresholds-cumulative rainfall thresholds matrix}

The previously-described approaches yielded good results, although both had some advantages and drawbacks. The CRT approach provided very good results in terms of reducing FAs but led to a relatively high number of missed alarms The IDT approach reduced the number of missed alarms but had a higher number of FAs. Furthermore, IDTs can better detect short and heavy rainfall, since these thresholds are continuous over the time interval, while CRTs analyse rainfall recorded in fixed time windows ( 1 day, 2 days, etc.) and could not provide good results with short and heavy rainfall events. On the other hand, IDTs are defined to identify critical rainfall events responsible for the landslide triggering, so these thresholds could not provide good results with longer and moderate rainfall events since, in this case, a critical event is not easily identifiable. CRTs can overcome this limitation as they also consider prolonged rainfall (30 days). To make the most from qualities (correct alarms) and lacks (missed alarms) of both CRT and IDT, and to take into account the different events that can be identified by both approaches, a contingency matrix between the two methods has been calculated. By using this matrix, it is possible to define a unique alert level on the basis of the alert level reached by each approach. To create this matrix, the number of landslides classified in each approach (from 2006 to 2017) has been compared and summarised into four alert levels:

1. No Warning: If the IDT approach result is No Warning, independent of the alert level reached by the CRT approach.

2. Standby: If IDTs result is Standby and CRTs result is No Warning or Standby, and if IDTs result is Caution and CRT is No Warning.

3. Caution: If IDTs result is Standby and CRTs result is Caution or Warning, and if IDTs result is Caution and CRTs is Standby.

4. Warning: If IDTs result is Caution and CRT result is Caution or Warning, and if IDTs result is Warning, independent of the alert level reached by CRT approach. 


\subsection{Landslide hazard mapping}

The first step in hazard mapping was the creation of a landslide inventory map, which was performed recognising geomorphological and hydrological features typically associated with landslides (scarps, ponds, bulging, debris, change in vegetation), through the visual inspection and interpretation of aerial and/or satellite photographs supported by field surveys for validation. This procedure allowed the mapping of 659 landslides (with unknown day of occurrence), the extents of which varied between 23.71 to $55,724 \mathrm{~m}^{2}$ with an average area of $2,079.6 \mathrm{~m}^{2}$. Considering the shape, most of the mapped phenomena can be classified as shallow landslides often developing into debris flows. To develop the hazard map, the second step of the work was to define the landslide conditioning variables (LCV) as a geological unit, land cover type, slope angle, rainfall pattern, slope curvature, contributing area, soil depth and soil saturation. In landslide analysis, most of the LCV are non-numeric and may assume only categorical values. Typical examples are geologic units (Mesozoic flysch, Cretaceous massive limestone, Pleistocene conglomerates) and land cover types (forest, pastureland, urban area, water, bare soils, crops). In such cases, the assignment of a numerical value is difficult and may only rely on subjective judgment of the different ranking of the LCV values with respect to the predisposition to mass movements. To perform the hazard (susceptibility) mapping, a machine learning method (MLM) called RF (Catani et al. 2013; Zhou et al. 2018) has been used. RF methods are ensemble classification trees based on binary and non-binary selection that are very flexible and may be used for both classification and regression problems. A single binary classification tree is a weak learner, but an ensemble of many trees may become a strong learner resulting in a very good classifier. Basically, for landslide analysis, RF works according to the following scheme:

1. A large dataset of LCV is created for the entire study area, with the best possible resolution for the landslide type and dimension.

2. Each LCV is defined both numerically and categorically in raster format.

3. A ground-truth map or database is collected with the actual landslides in the study area.

4. The ground-truth dataset is divided into three parts: training, calibration and validation.

5. A random sampling of all datasets is created and used to sample them.

6. The sample data for RF training and calibration is fed (together with ground-truth data) to the MLM system that selects the best RF structure and ranks LCV by relative importance.

7. The sample data are used to generate landslide forecasting.

8. The calibration data are used to check accuracy and errors by receiver operating characteristic (ROC) curves.

9. A new larger random sample is generated with only LCV values (no output). RF system produces predictions.

10. A validation is performed by comparison with validation landslides.

11. A susceptibility map is generated for the area by inverse mapping and interpolation, with hazard classes ranked according to comparison to the actual knowledge of the area.

A secondary but still important assessment, even though averaged for the catchment scale, concerns the estimation of landslide magnitude (mainly dimension as surface area) and runout path convergence and density. These are basic parameters needed for achieving a basin-scale understanding of what can be expected from susceptible areas in terms of sediment transport, new landslide dimension and runout path density and probabilities. By following the approach recently proposed by Catani et al. (2016), the starting point for the magnitude analysis is the computation of landslide area derived from the mapping of aerial images. As stated, a total of 659 landslide polygons have been digitised to an approximately 1:10,000 scale with areal dimensions ranging from 25 to $55,000 \mathrm{~m}^{2}$. Given an average regolith depth of $2.5 \mathrm{~m}$ on the slopes (which is affected by a high standard deviation), volumes ranging from $10^{2}$ to $10^{5} \mathrm{~m}^{3}$, with outliers that can reach up to $10^{6} \mathrm{~m}^{3}$, may be expected. For the runout path density estimation, we started from the digital elevation model (DEM) of the 
area and collected all the derived data on drainage network, channels, slope flow directions and accumulation of water to infer possible sediment arrival positions. Then, for each sediment convergence spot, common average watershed geometry parameters were computed and a relative estimation of the expected volumes during storms triggering debris flows was achieved. The estimation is based on a set of variables generally thought to influence runout and transport capacity. From the geometry point of view, by recurring to DEM analysis and hydrological reconstruction of the stream network by contributing area thresholds, several potential convergence points have been highlighted where higher than average sediment arrival can be expected. Then, for each sub-watershed in the study area, some basic basin parameters have been extracted and used to compute a relative measure of expected sediment runout volume over a given time cycle, approximately equal to the average duration of rainfall intensity pulses.

\subsection{Development of the early warning system}

The implementation of rainfall thresholds for the prediction of possible shallow landslide occurrences, due to heavy rainfall in an operational monitoring and early warning chain is completed with the setup of a realtime monitoring tool capable of incorporating the identified rainfall thresholds, the time synchronisation and the continuous record of rainfall by ground stations. The EWS tool works using the threshold approaches described in the previous section and also by their combination on the basis of the confusion matrix described in Section 2.1.3. The program is an executable file, which can be launched by a command line, inputting some external parameters about the operation to be performed and the data to be used. The use of the external parameters (stored in an editable file) allows for the adaptation of the program to different environments and for its use with different data, logic or output. The program is developed to use continuous rainfall data derived from rain gauges available on the territory. The output of the procedure is a comma-separated values (CSV) file that can be joined to an existing geographic information system (GIS) file to have a visual and geographical representation of the forecast. The program works on a rain gauge base. Every rain gauge is analysed separately from others using parameters stored in a specific configuration file. During the procedure, for each rain gauge, several data are stored to memorise current and past status of the EWS.

\section{$3 \quad$ Results}

\subsection{Rainfall thresholds}

\subsubsection{Intensity-duration thresholds}

The IDT approach allowed definition of three thresholds (Table 2), hence four alert levels as showed in Figure 4. This approach allowed the classification the majority of landslides, since only $3 \%$ of landslide events (three landslides) were classified in the No Warning levels as reported in Table 3.

Table 2 Equation of the thresholds

\begin{tabular}{ll}
\hline Threshold & Equation \\
\hline Standby & $I=7.5 D^{-0.68}$ \\
Caution & $I=16.5 D^{-0.68}$ \\
Warning & $I=33 D^{-0.68}$ \\
\hline
\end{tabular}




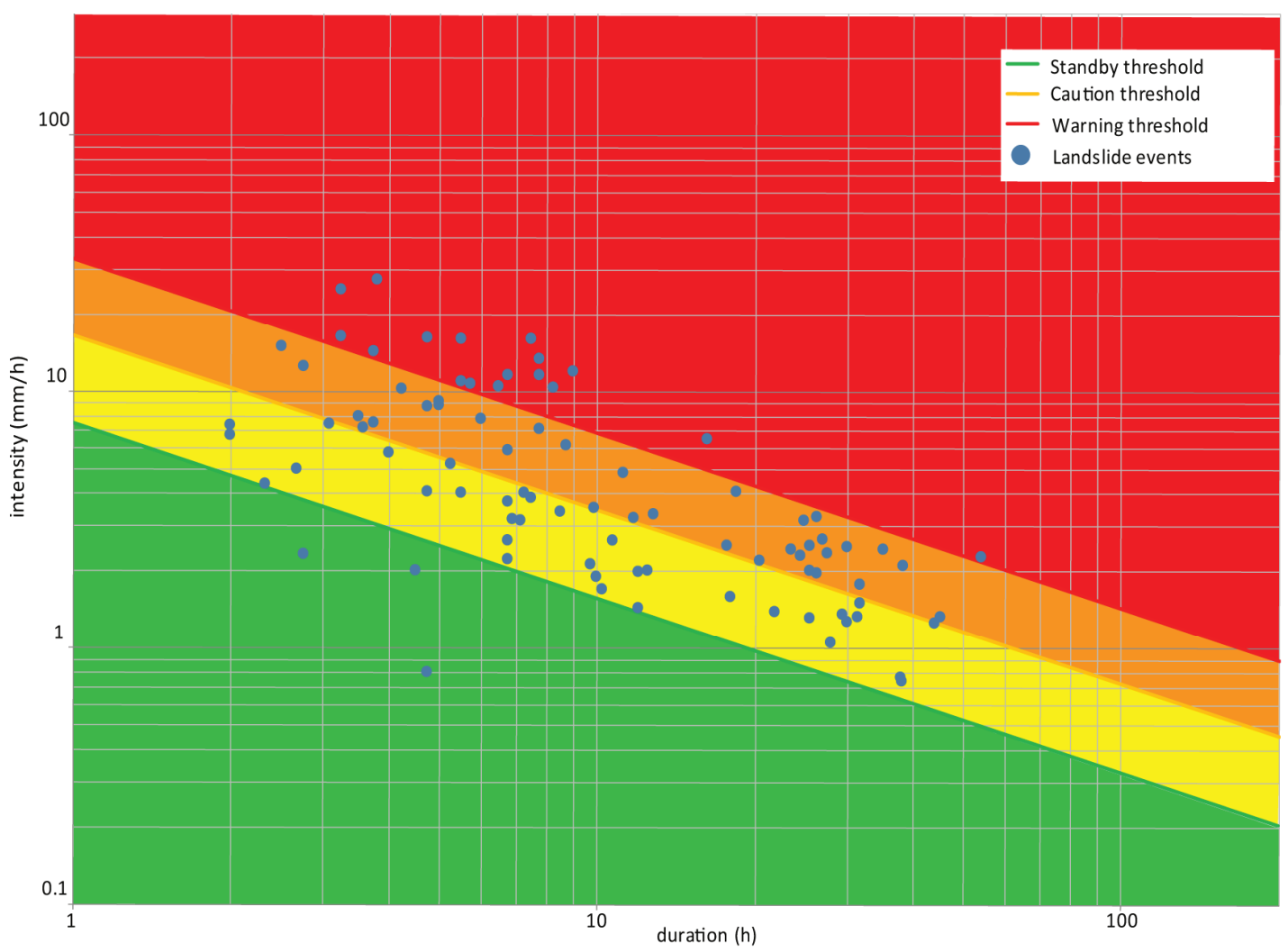

Figure 4 Alert levels defined by the threshold system

Table 3 Rainfall events and landslide distribution over the four alert levels

\begin{tabular}{lll}
\hline Alert level & $\begin{array}{l}\text { Rainfall events } \\
\text { triggering landslides }\end{array}$ & $\begin{array}{l}\text { Number of } \\
\text { landslides }\end{array}$ \\
\hline Warning & $17(18 \%)$ & $54(40 \%)$ \\
\hline Caution & $36(39 \%)$ & $36(27 \%)$ \\
\hline Standby & $36(39 \%)$ & $41(31 \%)$ \\
\hline No Warning & $3(3 \%)$ & $3(2 \%)$ \\
\hline Total events & 92 & 134 \\
\hline
\end{tabular}

To verify the quality of the threshold system, a validation also considering rainfall that did not triggered landslides, has been carried out.

The validation has been conducted comparing all rainfall events (both triggering and not triggering landslides) from 2006 to 2017, with the threshold system.

The validation showed that about $85 \%$ of all events are classified as 'No Warning', about $12 \%$ as 'Standby', about 3\% as 'Caution' and $0.1 \%$ as 'Warning'. Landslide triggering events were $40 \%$ in Warning level, $27 \%$ in Caution level, $31 \%$ in Standby and $0.2 \%$ in No Warning. 


\subsubsection{Cumulative rainfall thresholds}

The results of the application of the algorithm developed with the CRT approach are reported in Table 4, where it is shown that the number of FA drastically reduce from No Warning level (142 FA) to the Warning level, where only 1 FA was reported in 5 years.

Table 4 Results of algorithm defined by the CRT approach

\begin{tabular}{llll}
\hline Alert level & $\begin{array}{l}\text { Overall rainfall } \\
\text { events }\end{array}$ & $\begin{array}{l}\text { Rainfall events } \\
\text { triggering landslides * }\end{array}$ & $\begin{array}{l}\text { Number of } \\
\text { landslides }\end{array}$ \\
\hline Warning & 13 & $12(92 \%)$ & 36 \\
\hline Caution & 32 & $14(44 \%)$ & 42 \\
\hline Standby & 162 & $20(12 \%)$ & 45 \\
\hline No Warning & 1,483 & $10(<1 \%)$ & 10 \\
\hline
\end{tabular}

*Percentages refer to the number of events of the corresponding levels

Once the algorithm was properly defined, a validation with an independent landslide dataset was carried out. To perform the validation, landslide and rainfall data from 2006 to 2012 were used. In total 71 landslide events were used and each of them was classified in one of the four alert levels (Table 5). Validation showed that in the Warning level, over 5 years, there are no FAs, while in Caution level only two FAs were present, with only 82 in the Standby level. During the same period, 19 events were classified as No Warning. These events are missed alarms; however, they are less than $1 \%$ of all events classified as No Warning $(2,402$ rainfall events).

Table 5 Result of validation of the cumulative rainfall thresholds approach

\begin{tabular}{lll}
\hline Alert level & Overall events & $\begin{array}{l}\text { Rainfall events } \\
\text { triggering landslides }\end{array}$ \\
\hline Warning & 17 & $17(100 \%)$ \\
\hline Caution & 7 & $5(71 \%)$ \\
\hline Standby & 112 & $30(27 \%)$ \\
\hline No Warning & 2,402 & $19(<1 \%)$ \\
\hline
\end{tabular}

Validation confirmed the result of the calibration and, in general, the result of the CRT approach can be considered satisfactory since it resulted in few FAs and also in a relatively low number of missed alarms.

\subsubsection{Intensity-duration thresholds-cumulative rainfall thresholds matrix}

The use of a confusion matrix to combine the IDT and CRT approaches allowed the reduction of both the high number of FAs provided by the IDT and the number of missed alarms provided by the CRT. By the combination of these approaches, 16 possible combinations were generated and grouped into four alert levels as described in Section 2.1.3 and shown in Table 6. 
Table 6 Contingency matrix between IDT and CRT approaches with the number of landslides recorded in each cell

\begin{tabular}{c|l|l|l|l|l}
\hline \multicolumn{2}{c|}{} & \multicolumn{5}{c}{ CRT } \\
\cline { 3 - 7 } \multicolumn{2}{c|}{} & No Warning & Standby & Caution & Warning \\
\hline \multirow{2}{*}{5} & No Warning & 2 & 1 & 0 & 0 \\
\cline { 2 - 7 } & Standby & 20 & 15 & 2 & 1 \\
\cline { 2 - 7 } & Caution & 4 & 11 & 3 & 14 \\
\cline { 2 - 7 } & Warning & 1 & 6 & 0 & 28 \\
\hline
\end{tabular}

By taking this approach, only three landslides were classified in No Warning, 39 in Standby, 14 in Caution and 52 in Warning levels.

\subsection{Hazard mapping}

By using the RF technique, a landslide susceptibility map of the study area was obtained. To keep the representation readable and to be usable in operational early warning or risk mitigation practices, the continuous output values of susceptibility are grouped in nine classes that optimally represent the state of the nature on the slopes of the area (Figure 5).

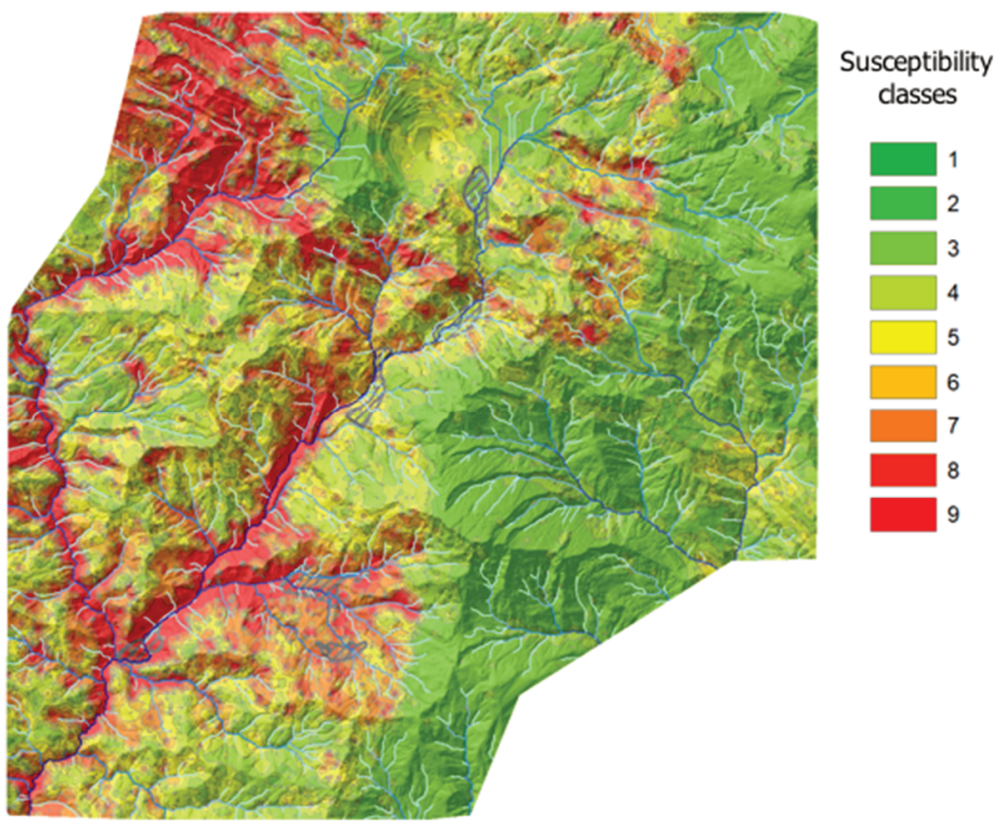

Figure 5 Landslide susceptibility map of the entire study area obtained by averaging the 20 model runs. The classification is made to highlight susceptibility differences with special reference to the town area

The final prediction has been analysed in several ways. Firstly, a ROC curve can be plotted for each model run reporting the trend of true and FAs (false positive rate versus true positive rate). To indicate an accurate prediction, the area under the ROC curve (a quantity usually referred to as 'area under the curve') must be maximised. In the case under study, the AUC values of each model run have an average value of 0.9904, which is very high and confirms the capability of the model to correctly explain the present situation of slope instability. The maximum AUC is 0.9920 and the minimum is 0.9892 . A forward validation has been attempted following the map definition, by comparing the susceptibility levels with the average positioning of some 
landslides that occurred on 24 December 2017 (Figure 6). Of a total of five new landslides, some of which are possibly related to stream bank failure or erosion, three of them fall in the susceptibility class 7 (high) and two in class 8 (very high). The most important parameters (LCV) that seem to condition the presence of shallow landslides in the study area, emerge from the RF analysis with a relative explained-variance approach. They are, in order of importance, geology of bedrock, biomass density, rain patterns and closeness of topography. The lesser importance of hydrological factors, quite unexpected, is probably due to the lack of knowledge regarding the soil and regolith depth, which may be crucial for a further improvement of the prediction map. It has been verified (Dai \& Lee 2001; Rosi et al. 2018) that landslide size follows an inverse frequency-size relationship that is ubiquitous in nature, indicating that there may be a few occurrences of very large mass movements as compared to a large number of small ones.

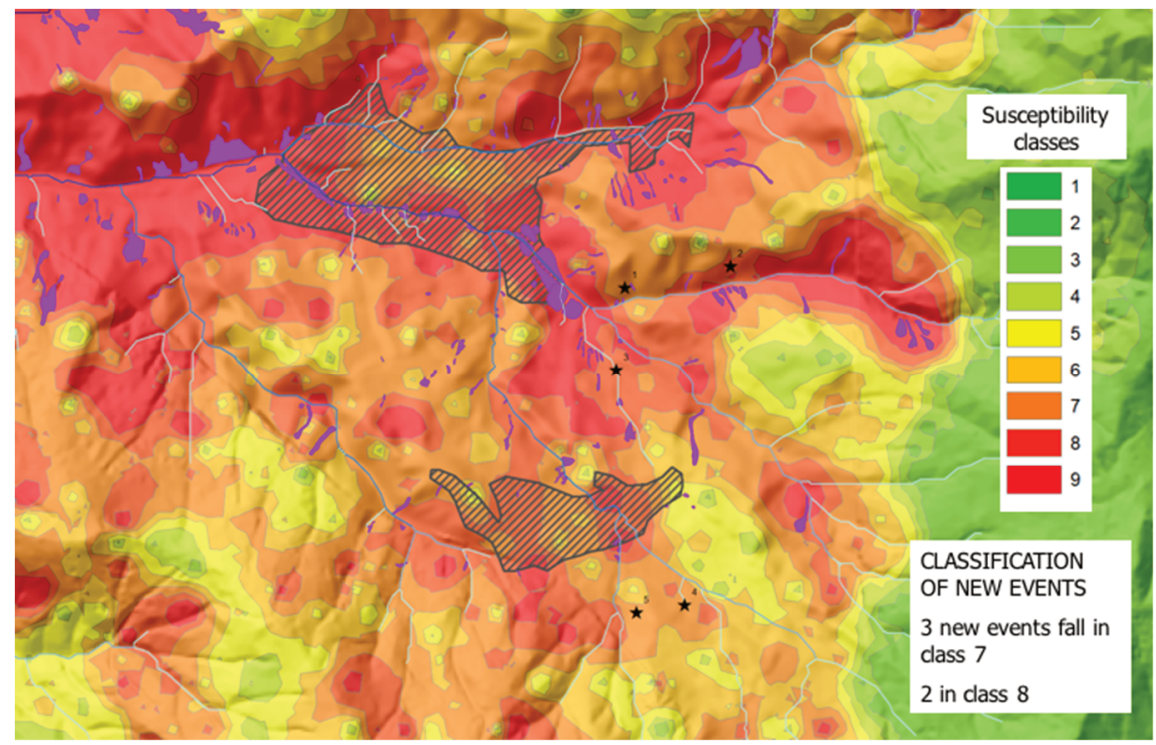

Figure 6 Detail of susceptibility map with new events of 24 December 2017 indicated as black stars

Starting from our dataset, comprising 659 landslide polygons, the frequency-size distribution of areal dimensions, ranging from 25 to $55,000 \mathrm{~m}^{2}$, was analysed. Given an average regolith depth of $2.5 \mathrm{~m}$ on the slopes, volumes ranging from $10^{2}$ to $10^{5} \mathrm{~m}^{3}$, with outliers that can reach up to $10^{6} \mathrm{~m}^{3}$, may be expected.

After fitting the most used probability distributions to the binned data, we found that the best performing equation is a double-exponential equation fitting the empirical landslide data very well (Figure 7).

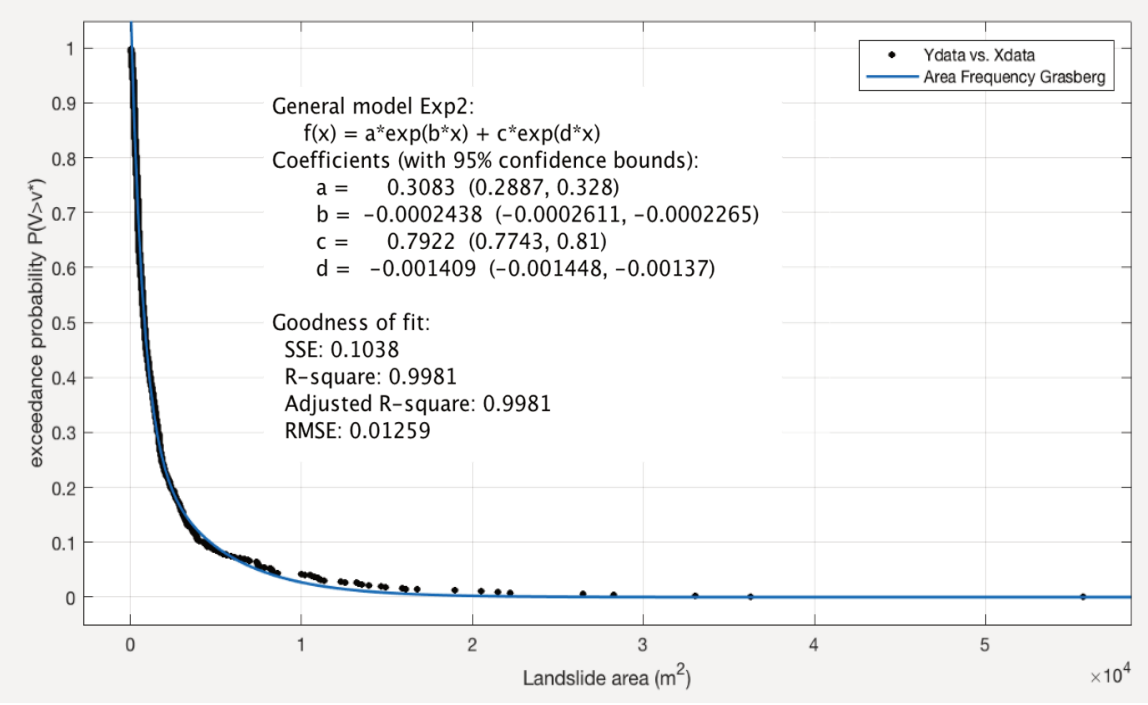

Figure 7 Fit of empirical data on landslide size in the study area. In the plot the double-exponential equation is reported along with the estimated 4-parameters values 
Runout analysis has been performed by the Gravitational Process Path (GPP) model (Wichmann 2017) that estimates process paths and runout area for a given landslide event based on DEM and calibration data.

The simulations that have been carried out have the following parameters and boundary conditions:

1. Random walk path search.

2. DEM resolution $10 \mathrm{~m}$.

3. Source areas defined by highest susceptibility class and slope threshold.

4. Runout modeling by shadow angle approach.

5. Modeling only applied to detail scale analysis for sub-basins.

The results include the maximum velocities in the source areas and the frequency of travelled paths, which is a good equivalent of runout area.

\subsection{Early warning system}

To verify the quality of the developed EWS, landslide data from 2018 have been used and the outputs of the model, which was used to simulate a real condition, have been compared with those events. In 2018, 31 landslide events were reported in the study area, causing several road closures and some work interruptions. The developed EWS-which was set to use the combined IDT-CRT approach-provided correct alerts in 26 cases, while in four cases any alert was issued and in one case it was not possible to verify the results since the landslide day of occurrence was missing. Considering 30 landslide events, the EWS correctly gave alerts in $87 \%$ of the cases ( 10 times Standby, nine times Caution and seven times Warning), missing only four landslides. Of the missed landslides, one event was a boulder fall, which reliably was not due to rainfall, while for the other three the EWS issued alarms the day before the events.

\section{Conclusion}

The aim of this work was to provide the PT Freeport Indonesia staff with the basis for the setup of alarms based on meteorological forecasts and rain gauge measurements to be used as a basis for a routine, continuous EWS to mitigate the risk for the Grasberg mine and surrounding valleys of the sudden detachment, routing and runout of shallow landslides. The work analysed two different approaches to identify the rainfall conditions capable of triggering landslides. One approach was based on the analysis of critical rainfall (IDT) and the other was based on the analysis of longer rainfalls. Since the results of both approaches were not completely satisfactory, due to the high number of FAs (IDT) or missed alarms (CRT), these approaches were combined by a confusion matrix. This matrix illustrated the pros of the approaches and minimised their drawbacks. The EWS was then developed using the new thresholds and their combination to provide real-time analysis of the rain condition in the studied area. The susceptibility analysis has been performed by using a machine learning multivariate statistical engine (RF) trained and then run for the entire study area. The results show a very good fitting from predictions and available ground-truth (average $A U C=0.99$ ) with the distribution of high-susceptibility areas along the base of main hillslopes draining to the larger valleys. The statistical significance of the different LCVs, computed by bootstrapping and jack-knife out-of-bag selection, reveals that the most important factors driving landslide processes in the study area are the litho-technical classes of the bedrock, the vegetation density, the rainfall pattern in terms of standard deviation of 48 hours cumulated events and some topographic factors, such as the slope angle and the protection index. The definition of impacted areas at the watershed scale was accomplished by a joint GIS analysis on sub-watershed, flow path and deposition areas, defined by the topographic information. An estimation of relative sediment yield at each outlet position has additionally been estimated by using an empirical formula considering susceptibility, energy relief and sediment delivery ratios. For two selected watersheds, an in-depth GPP-model (gravitational process path) model analysis has also been done, which reveals areas potentially dangerous for both debris-flow travelling and deposition. 


\section{Acknowledgement}

The authors thank PT Freeport Indonesia for having funded and proactively supported the activities described in the paper.

\section{References}

Benedetti, A, Casagli, N, Bosi, V, Dapporto, S, Ciolli, S, Palmieri, M \& Zinoni, F 2005, 'Modello statistico per la previsione operativa dei fenomeni franosi nella regione Emilia-Romagna' (Statistical model for the operational forecast of landslides in the EmiliaRomagna region), Boll Soc Geol Italy, vol. 124, pp. 333-344.

Brunsden, D 1973, 'The application of system theory to the study of mass movement', Geol Appl Idrogeoeol, vol. 8, pp. $185-207$.

Caine, N 1980, 'The rainfall intensity-duration control of shallow landslides and debris flows', Geografiska Annaler, vol 62, pp. $23-27$.

Catani, F, Lagomarsino, D, Segoni, S \& Tofani, V 2013, 'Landslide susceptibility estimation by Random Forests technique: sensitivity and scaling issues', Natural Hazards and Earth System Sciences, vol. 13, pp. 2815-2831.

Catani, F, Tofani, V \& Lagomarsino, D 2016, 'Spatial patterns of landslide dimension: A tool for magnitude mapping', Geomorphology, vol. 273, pp. 361-373.

Dai, FC \& Lee, CF 2001, 'Frequency-volume relation and prediction of rainfall-induced landslides', Engineering Geology, vol. 59, pp. 253-266.

Goovaerts, P 1997, Geostatistics for natural resources evaluation, Oxford University Press, Oxford.

Martelloni, G, Segoni, S, Fanti, R \& Catani, F 2012, 'Rainfall thresholds for the forecasting of landslide occurrence at regional scale', Landslides, vol. 9, issue 4, pp. 485-495.

Guzzetti, F, Peruccaci, S, Rossi, M \& Stark, CP 2007, 'Rainfall thresholds for the initiation of landslides in central and southern Europe', Meteorology and Atmospheric Physics, vol. 98, pp. 239-267.

Petley, D 2012, 'Global patterns of loss of life from landslides', Geology, vol. 40, pp. 927-930.

Rosi, A, Peternel, T, Jemec-Auflič, M, Komac, M, Segoni, S \& Casagli, N 2016, 'Rainfall thresholds for rainfall-induced landslides in Slovenia', Landslides, vol. 13, pp. 1571-1577.

Rosi, A, Segoni, S, Battistini, A, Rossi, G, Catani, F \& Casagli, N 2017, 'Definition of a fully functional EWS based on rainfall thresholds, the case of study of Tuscany Region', Proceedings of the Workshop on World Landslide Forum, Springer, Cham, pp. 169-174.

Rosi, A, Canavesi, V, Segoni, S, Dias Nery, T, Catani, F \& Casagli, N 2019, 'Landslides in the mountain region of Rio de Janeiro: a proposal for the semi-automated definition of multiple rainfall thresholds', Geosciences, vol. 9, doi: 10.3390/geosciences9050203

Rosi, A, Tofani, V, Tanteri, L, Stefanelli, CT, Agostini, A, Catani, F \& Casagli, N 2018, 'The new landslide inventory of Tuscany (Italy) updated with ps-insar: Geomorphological features and landslide distribution', Landslides, vol. 15, pp. 5-19.

Segoni, S, Rosi, A, Fanti, R, Gallucci, A, Monni, A \& Casagli, N 2018,' A regional-scale landslide warning system based on 20 years of operational experience', Water, vol. 10, https://doi.org/10.3390/w10101297

Wichmann, V 2017, 'The gravitational process path (GPP) model (v1.0) - a GIS-based simulation framework for gravitational processes', Geoscientific Model Development, vol. 10, pp. 3309-3327.

Zhou, C, Yin, K, Cao, Y, Ahmed, B, Li, Y, Catani ,F \& Pourghasemi, HR 2018, 'Landslide susceptibility modeling applying machine learning methods: A case study from Longju in the Three Gorges Reservoir area, China', Computers and Geosciences, vol. 112, pp. 23-37. 